\title{
Experimental study on the behavior of waste marble powder as partial replacement of sand in concrete
}

\author{
Abdul Ghani ${ }^{1}$ - Zeeshan Ali ${ }^{1}$ - Fasih Ahmed Khan ${ }^{1}$ (1) - Said Rehan Shah ${ }^{1} \cdot$ Sajjad Wali Khan $^{1,2}$. \\ Muhammad Rashid ${ }^{1}$
}

Received: 4 April 2020 / Accepted: 17 August 2020 / Published online: 25 August 2020

(c) Springer Nature Switzerland AG 2020

\begin{abstract}
The increase in the concrete demand due to the rapid industrialization and urbanization may lead to a shortage of natural resources. Therefore, the use of recycled material in the batching of concrete will be helpful to meet the demands of the time without compromising the quality of concrete production. One such waste material produced in Pakistan is waste marble powder (WMP) that is generated from the marble factories during cutting of the marble stones, which in turn have a damaging effect on the environment. This study is based on the utilization of WMP as a partial substitute of the sand in concrete production and its various effect on the mechanical properties of the concrete. Different types of tests (unit weight, workability, compressive strength, splitting tensile strength, and water penetration) were carried out at $0-80 \%$, of sand replaced with WMP, at increments of $20 \%$. In all mixes, the ratio of water to cement was kept constant and the effects of curing conditions were studied at 14,28 , and 70 days. It was observed that with the incorporation of WMP, the workability and unit weight of concrete decrease proportionally to replacement percentage, whereas mechanical properties of concrete increase up to a certain percentage and then decrease. The maximum improvement in compressive strength was achieved at a $40 \%$ replacement, with a slight improvement in the tensile strength at $20 \%$ replacement. The water penetration test revealed a decrease in permeability with the increase in WMP percentage. Based on the results, it was recommended to use WMP up to $40 \%$ in the concrete mix as a replacement of sand.
\end{abstract}

Keywords Concrete $\cdot$ Marble waste $\cdot$ Compressive strength $\cdot$ Sand replacement $\cdot$ Environment

\section{Introduction}

The estimated values for the world marble reserves are approximately 15 billion cubic meters, and marble industries are working in almost fifty countries globally [1]. In Pakistan, the estimated marble reserves are more than 300 billion tons [2, 3]. During the fiscal year 2016-2017, 4.9 million tons of marble were produced in Pakistan, of which more than 2.15 million tons were produced in the province of Khyber Pakhtunkhwa Province (KPK), 1.92 million tons in Balochistan, and 0.82 million tons in FATA region [4]. The factories in Pakistan utilize water for the cutting of the marble stones, which in turn generate a lot of waste marble slurry, upon drying this slurry turns into waste marble

Electronic supplementary material The online version of this article (https://doi.org/10.1007/s42452-020-03349-y) contains supplementary material, which is available to authorized users.

Zeeshan Ali, engrali580@gmail.com; 15jzciv0013@uetpeshawar.edu.pk; Abdul Ghani, ghania866@gmail.com; 15jzciv0026@ uetpeshawar.edu.pk; Fasih Ahmed Khan, fasihahmad@uetpeshawar.edu.pk; Said Rehan Shah, engr.rehan253@gmail.com; 15jzciv0003@ uetpeshawar.edu.pk; Sajjad Wali Khan, drsajjadwalikhan@uetpeshawar.edu.pk; Muhammad Rashid, mrashidad@gmail.com; 14pwciv4073@uetpeshawar.edu.pk|'Civil Engineering Department, University of Engineering and Technology Peshawar, Peshawar, Pakistan. ${ }^{2}$ Loughborough University, Loughborough, UK. 
powder (WMP), having 90 percent of the particles' size less than $200 \mu \mathrm{m}$ after drying out of the slurry shape [5], which in turn is harmful to the environment [6-8].

Marble blocks are extracted from the quarries and processed at marble factories. Dust and broken aggregates are the by-products of marble, produced in the marble processing like cutting and polishing stages [9]. Around $20-30 \%$ of the marble blocks transform into powder residue. Millions of tons of waste material are produced in this process which is blindly disposed of to a nearby environment $[10,11]$. In Pakistan, District Buner of KPK is the main hub of marble production; huge amounts of WMP are generated which affects the natural environment and water bodies badly in that region. More than $\mathbf{4 0 0}$ marble industries are located in the Buner district, Pakistan [12]. Other cities which also have the high marble production capacities and hence are vulnerable to WMP include Swat, Swabi, Peshawar, Chitral, Kohistan, Mardan, Hazara, Nowshera, and Kohat [13]. Water quality of both surface and underground sources is declining in Swat, Pakistan, because of waste generation from marble factories [14]. The waste slurry created is aimlessly dumped on empty land, waterway banks, and wood regions. Due to the high degree of fineness of the slurry particles, pores within fertile soil are filled by these particles which prevent the water percolation in the soil and reduce its fertility. Slurry particles when dried are lifted into the air, by winds, and can bring about respiratory issues to nearby people $[15,16]$.

To cope with such overexploitation of the resources and negative impacts of WMP on the environment, it is therefore important to consume and treat these wastes in a well-planned manner and legitimize the use of WMP in the development of auxiliary concrete mixes [1, 17]. Mineral admixtures can be effectively and economically used to improve the properties of these mixes, both in their fresh and hardened states [18]. WMP can be used not only as admixtures or additive but also to produce other types of building material, such as ceramic bricks [19].

Concrete is the second most used building material at a variety of construction activities on the planet Earth. Concrete is a composite blend of cement, fine aggregate and coarse aggregate, and water [20]. The aggregates occupy almost $70-75 \%$ of the concrete volume, and therefore, the properties of aggregates play a significant role in the physical, mechanical, and chemical properties of the concrete in its fresh and hardened state [21].

The utilization of virgin resources like fine aggregate and coarse aggregate in concrete may lead to a shortage of good quality aggregates. Factors associated with the large-scale use of the resources are the growth of population, technological advancement, industrialization, and the desire to arrive at a better quality of life for the people. As an outcome, the idea of manageability has developed, characterized as a harmony between the utilization and assurance of a good future life [22]. Therefore, the usage of some alternative resources is the utmost need of the hour to maintain natural quarries.

The study on the use of WMP in concrete has been done by many researchers. In a research study carried out by Hebhoub et al. [23], three sequences of concrete mixtures were prepared with waste marble aggregates as a sand replacement, coarse aggregate replacement, and both fine and coarse aggregates replaced in mixtures. In their study, $50 \%$ sand replacement mixtures showed $23.65 \%$ gain in compressive strength at 28 days as compared to the coarse aggregate mixture that did not achieve any significantly enhanced strength, and the decrease in workability was noted for all concrete mixes. Another study conducted by Ulubeyli and Artir [24] showed an increase of 5-10\% in the mean strengths with the incorporation of marble powder as fine aggregate replacement. In a research study by Alyamac and Aydin [1], WMP showed the maximum gain in compressive strength at a $40 \%$ level as a sand substitute. A study by Syed Ahmed Kabeer and Ashok [25] noted an increase in bulk fresh density of concrete with WMP incorporated as sand replacement, and density was increased up to $20 \%$ replacement of sand but decreased beyond $40 \%$. The effectiveness of WMP in the paving blocks was studied by Gencel et al. [10], and it was observed that WMP decreases the dry density of the blocks when compared with the control mix. The use of WMP has shown improved results in high-performance concrete [18]. The use of WMP, in self-compacting concrete (SCC), was also investigated, and the WMP was used as a fine aggregate replacement up to $100 \%$. Along with plasticizers, the use of WMP was done with a w/c ratio of 0.28 to improve the workability. It was found that SCC showed satisfactory results up to $25 \%$ replacement of fine aggregate as WMP at 28 days and 56 days of curing [26].

Aliabdo et al. [27] investigated the use of marble dust as cement replacement with two water-to-cement ratios $(\mathrm{w} / \mathrm{c})$, i.e., 0.4 and 0.5 . It was concluded from their research that the cement replacement shows effectiveness up to a $10 \%$ replacement level. In another study conducted by Shamsul Khaliq et al. [16] on the effectiveness of WMP as a cement replacement, the source that was used was from Peshawar and Karachi (cities located in Pakistan). The conclusion to their study was that the use of WMP reduced the compressive strength and improved permeability at $5-10 \%$ replacement.

The process of recycling material is similar to the creation of a new product. Uses of waste material in concrete can decrease the utilization of natural resources and limit ecological contaminations. If the WMP is utilized in the concrete as a partial replacement of the fine aggregate, then it would reduce the consumption of sand and the 
waste material can be deposited in a structure without causing the pollution and damaging the natural environment. In developing countries, the demand for natural sand is very high due to the rapid development of infrastructure resulting in a shortage of stocks [17, 27-30].

A lot of research work is carried out on the use of WMP in concrete as fine aggregate and cement, but less work is carried out on the partial replacement of sand with WMP having higher dosage of WMP without changing the $\mathrm{w} / \mathrm{c}$ ratio. The WMP used in various research works is shown in Table 1, which indicates that the chemical composition of WMP varies from source to source $[1,24$, $25,31-33]$ and its effect on the concrete mix can vary as well. The WMP used in this research is collected from the District Buner of Pakistan, and its chemical composition is reported in Table 4, which are different in comparison with the WMP reported in other studies. Similarly, a lot of work is carried out on the compressive strength and tensile strength of WMP concrete, but a limited amount of work is carried on the permeability of concrete with a large amount of WMP as replacement of fine aggregate. In this research, the WMP is used as a sand replacement up to $80 \%$ with an increment of $20 \%$, to evaluate the properties of concrete like fresh density, workability, compressive strength at various ages of testing, tensile strength at various ages, and water permeability of concrete at various days of testing concrete. This will encourage the local construction industry to use WMP in concrete with confidence, which will ultimately help in reducing the adverse effects of it on the environment.

\section{Research significance}

The goal of this research is to examine the utilization of WMP as a partial substitution of sand and to study its impact on the fresh and hardened properties of concrete. The current experimental study is an effort to develop alternative materials for use in concrete without compromising its properties. This will not only help in the reduction in the environmental and health issues arising due to the inappropriate disposal of WMP but also control the depletion of natural resources. Such experimental studies will also encourage the local industry to use WMP with confidence in concrete.

\section{Materials}

Materials selection was based on the criteria set in the ASTM standards. The following section describes the details of materials and relevant tests performed on a different set of materials.

Table 1 Different compositions of WMP used by previous authors

\begin{tabular}{|c|c|c|c|c|c|c|c|}
\hline Authors & $\mathrm{SO}_{3}(\%)$ & $\mathrm{MgO}(\%)$ & $\mathrm{CaO}(\%)$ & $\mathrm{Fe}_{2} \mathrm{O}_{3}(\%)$ & $\mathrm{Al}_{2} \mathrm{O}_{3}(\%)$ & $\mathrm{SiO}_{2}(\%)$ & Other parameters \\
\hline Shukla et al. [34] & 0.1 & 0.1 & 58.1 & 0.2 & 0.1 & 0.8 & $\mathrm{~K}_{2} \mathrm{O}-0.1$ \\
\hline Varadharajan [7] & 0.11 & 15.55 & 41.64 & 0.821 & 0.56 & 5.77 & $\mathrm{~K}_{2} \mathrm{O}-0.073, \mathrm{Na}_{2} \mathrm{O}-0.07$ \\
\hline Singh et al. [35] & - & 16.9 & 28.63 & 0.78 & 4.62 & 3.86 & LOI-43.3 \\
\hline Khodabakhshian et al. [8] & - & 0.08 & 55.64 & 0.21 & 0.09 & 0.12 & $\begin{array}{l}\mathrm{Na}_{2} \mathrm{O}-0.01 \\
\mathrm{LOI}-43.76\end{array}$ \\
\hline Kabeer and Vyas [25] & - & 19.85 & 32.19 & 1.18 & 0.18 & 1.57 & LOI-45.07 \\
\hline Ashish et al. [36] & 0.33 & 14.36 & 61.8 & 0.65 & 0.67 & 8.38 & - \\
\hline Khyaliya et al. [37] & 0.56 & 0.52 & 83.22 & 0.05 & 0.73 & 1.12 & $\mathrm{~K}_{2} \mathrm{O}-0.09, \mathrm{Na}_{2} \mathrm{O}-1.12, \mathrm{LOI}-2.5$ \\
\hline Sutcu et al. [38] & - & 0.76 & 52.9 & - & 0.87 & 3.72 & $\begin{array}{l}\mathrm{K}_{2} \mathrm{O}-0.27 \\
\mathrm{LOI}-41.3\end{array}$ \\
\hline Vardhan et al. [39] & 0.09 & 15.21 & 40.73 & 0.8 & 0.6 & 6.01 & $\begin{array}{l}\mathrm{K}_{2} \mathrm{O}-0.05 \\
\mathrm{Na}_{2} \mathrm{O}-0.06\end{array}$ \\
\hline Aliabdo et al. [27] & 0.56 & 0.52 & 83.22 & 0.05 & 0.73 & 1.12 & - \\
\hline Sounthararajan and Sivakumar [40] & 0.10 & 0.36 & 51.49 & 0.33 & 0.70 & - & $\begin{array}{l}\mathrm{K}_{2} \mathrm{O}-0.25 \\
\mathrm{Na}_{2} \mathrm{O}-0.19 \\
\mathrm{LOI}-44.60\end{array}$ \\
\hline Ergün [41] & 0.08 & 0.40 & 51.70 & 0.44 & 0.67 & 0.18 & $\begin{array}{l}\mathrm{K}_{2} \mathrm{O}-0.21 \\
\mathrm{LOI}-46.04\end{array}$ \\
\hline Aruntaş et al. [42] & - & 0.59 & 54.43 & 0.08 & 0.12 & 0.67 & LOI-43.4 \\
\hline
\end{tabular}


Table 2 Properties of coarse aggregate

\begin{tabular}{llc}
\hline Description & Test standard & Value \\
\hline Bulk specific gravity (SSD) & ASTM-C127 [44] & 2.66 \\
Absorption capacity (\%) & ASTM-C127 [44] & 1.13 \\
Moisture content (\%) & ASTM-C566 [45] & 0.26 \\
Rodded unit weight (lbs/ft ${ }^{3}$ ) & ASTM-C29 [46] & 103.1 \\
Maximum size of coarse aggregate (in) & ASTM-C136 [47] & 0.75 \\
\hline
\end{tabular}

Table 3 Properties of fine aggregate

\begin{tabular}{llrl}
\hline Description & Test standard & Sand & WMP \\
\hline Specific gravity (SSD) & ASTM-C128 [48] & 2.45 & 2.41 \\
Absorption capacity (\%) & ASTM-C128 [48] & 3.30 & 0.34 \\
Bulk density/unit weight (lbs/ft $\left.{ }^{3}\right)$ & ASTM-C29 [46] & 92.13 & 84.75 \\
Moisture content (\%) & ASTM- C566 [45] & 2.22 & - \\
Fineness modulus & ASTM-C136 [47] & 3.00 & 0.99 \\
\hline
\end{tabular}

\subsection{Cement}

Ordinary Portland cement (OPC) produced by a local manufacturer (Cherat Cement Company) was used as a binding material. Fineness test was performed on OPC as per ASTM C184 [43], which was about $96.25 \%$. The specific gravity of cement was 3.15.

\subsection{Coarse aggregate}

The coarse aggregates used in the current research work were from a local quarry known as "Basai" located in KPK, Pakistan. Table 2 reports the different properties of these aggregates regarding ASTM standards.

\subsection{Sand and waste marble powder}

Natural coarser sand was used in the current research with the fineness modulus (F.M $=3$ ). This coarse sand was used to keep a mix balance in the gradation of aggregates because of the very fine nature of WMP. WMP was collected from Buner District, Khyber Pakhtunkhwa. Various tests required for characterizing sand and WMP, as fine aggregates, required for the design of concrete mixes were conducted, as per relevant ASTM standards. Table 3 reports the properties of the fine aggregate. WMP utilized in the current research was a fine powder of white color as shown in Fig. 1, and the gradation curves are shown in Fig. 2.

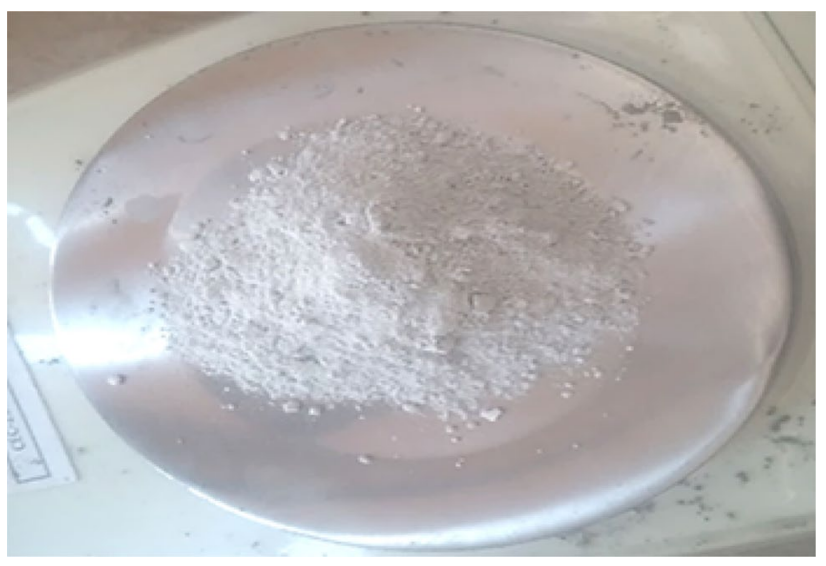

Fig. 1 Waste marble powder

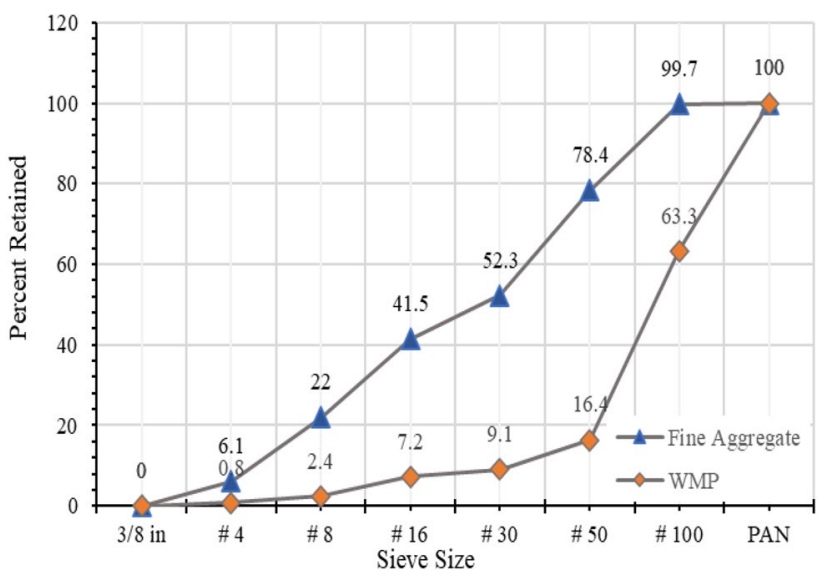

Fig. 2 Gradation curves of sand and WMP

\subsection{Chemical analysis of WMP}

Marble is a metamorphic rock that is composed of either calcite or dolomite. Colorless or light-colored marbles are a very pure source of calcium carbonate. Such a pure source of WMP was used in this study. However, the composition often varies and may contain impurities based on the geological properties of the location of the source. $\mathrm{X}$-ray fluorescence (XRF) and X-ray diffraction (XRD) tests were performed at the Central Research Lab in the Physics Department at the University of Peshawar, Pakistan, to study the chemical and mineralogical composition of WMP. Table 4 reports the chemical composition of the WMP, and the test results indicate that WMP contained $99 \% \mathrm{CaCO}_{3}$ which on ignition starts a chemical reaction and reduces to $55.45 \% \mathrm{CaO}$ and other compounds less than $1 \%$. The loss of ignition (LOI) of 43.58 was observed, and previous research indicates that $\mathrm{LOI}$ for WMP is very common in between the range of $40-45$ approximately 
Table 4 Chemical composition of WMP

\begin{tabular}{lclc}
\hline Compound & Content $(\%)$ & Compound & Content (\%) \\
\hline Calcium oxide $(\mathrm{CaO})$ & 55.45 & Titanium oxide $\left(\mathrm{TiO}_{2}\right)$ & 0.057 \\
Iron oxide $\left(\mathrm{Fe}_{2} \mathrm{O}_{3}\right)$ & 0.678 & Nickel oxide $(\mathrm{NiO})$ & 0.02 \\
Strontium oxide $(\mathrm{SrO})$ & 0.097 & Manganese oxide $(\mathrm{MnO})$ & 0.019 \\
Copper oxide $(\mathrm{CuO})$ & 0.045 & LOI & 43.58 \\
\hline
\end{tabular}

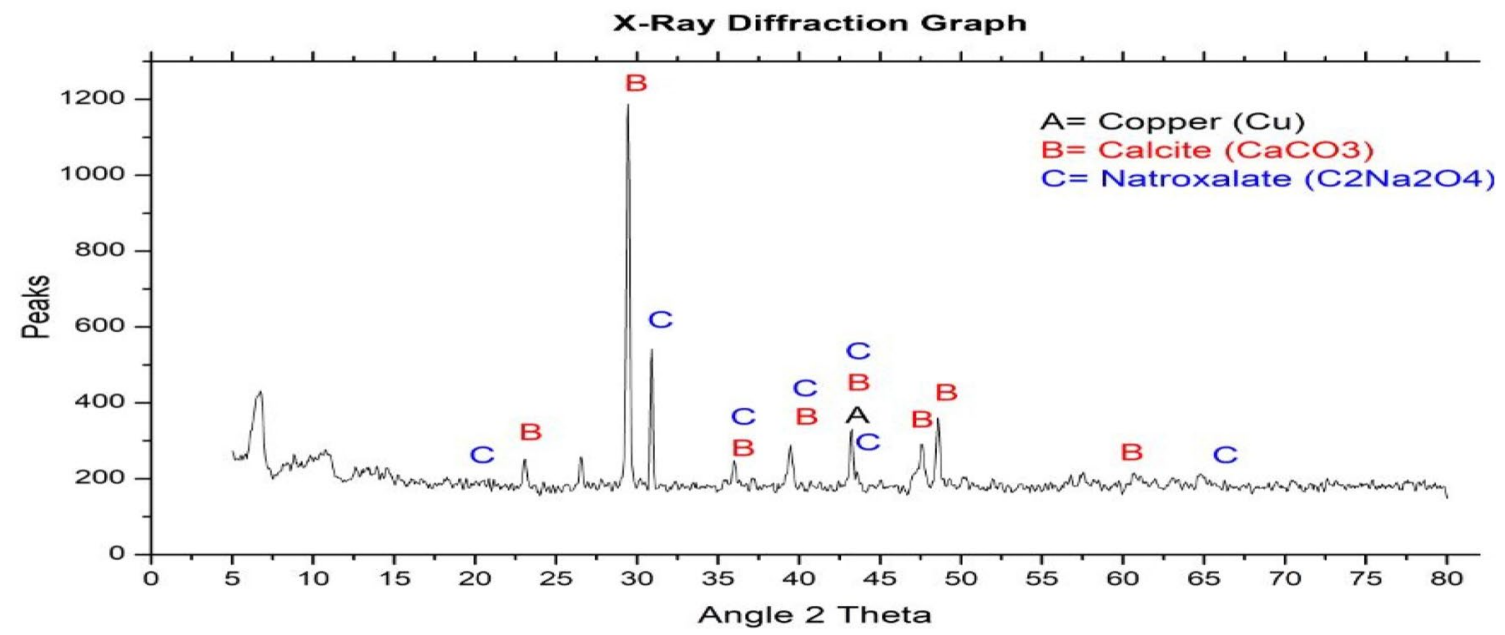

Fig. 3 XRD pattern of waste marble powder

Table 5 Concrete mix design for different mixes

\begin{tabular}{lllllc}
\hline $\begin{array}{l}\text { Sand replace- } \\
\text { ment (\%) }\end{array}$ & Water $\left(\mathrm{lb} / \mathrm{ft}^{3}\right)$ & Cement $\left(\mathrm{lb} / \mathrm{ft}^{3}\right)$ & Sand $\left(\mathrm{lb} / \mathrm{ft}^{3}\right)$ & Crush $\left(\mathrm{lb} / \mathrm{ft}^{3}\right)$ & WMP $\left(\mathrm{lb} / \mathrm{ft}^{3}\right)$ \\
\hline SR-0 & 13.67 & 22.09 & 51.23 & 62.02 & 0 \\
SR-20 & 13.67 & 22.09 & 40.98 & 62.02 & 10.24 \\
SR-40 & 13.67 & 22.09 & 30.74 & 62.02 & 20.49 \\
SR-60 & 13.67 & 22.09 & 20.49 & 62.02 & 30.74 \\
SR-80 & 13.67 & 22.09 & 10.24 & 62.02 & 40.98 \\
\hline
\end{tabular}

based on the purity of marble samples. XRD pattern shown in Fig. 3 authenticates the main phases in WMP to be calcite $\left(\mathrm{CaCO}_{3}\right)$ and natroxalate $\left(\mathrm{Na}_{2} \mathrm{C}_{2} \mathrm{O}_{4}\right)$.

\subsection{Concrete mix design}

Suitable mix design was carried out for the concrete using $\mathrm{ACl}$ 211.1. Different trials were selected before finalizing the control mix (SR-0). The finalized mix design was having 28 days compressive strength of 4000 psi with the $\mathrm{w} / \mathrm{c}$ ratio of 0.62 which was kept the same for all mixes. Five different mixes of concrete with $0 \%, 20 \%$, $40 \%, 60 \%$, and $80 \%$ replacement of sand by WMP as fine aggregate were prepared. Table 5 reports the mix proportions for each mix. Table 6 shows the designation of mixes corresponding to a different percentage
Table 6 Designation of different mixes

\begin{tabular}{ll}
\hline Designation & Sand replacement \\
\hline SR-0 & Control mix by weight \\
SR-20 & $20 \%$ of sand replacement with WMP by weight \\
SR-40 & $40 \%$ of sand replacement with WMP by weight \\
SR-60 & $60 \%$ of sand replacement with WMP by weight \\
SR-80 & $80 \%$ of sand replacement with WMP by weight \\
\hline
\end{tabular}

replacement of WMP by weight. The slump value selected for the given mix was between 3 and 4 inches. The $w / c$ ratio was selected based on the conventional concrete used in the region for low-rise buildings without the use of any plasticizers. 


\subsection{Tests on fresh and hardened concrete}

The experimental program for this research consists of two types of testing: the testing of the concrete in a fresh state and the test on the concrete in the hardened state. The slump test was carried out in a fresh state using ASTM C143 [49], and the bulk density of concrete was determined as per ASTM C138 [50]. The concrete compressive strength was calculated as per ASTM C39 [51], and their cylindrical (6-inch diameter and 12 in height) specimen was prepared and cured as per ASTM C192 [52]. For the tensile strength of concrete, these cylinders were tested as per ASTM C496 [53] and the water permeability/penetration test was done as per DIN-1048-V [54] which were conducted on the hardened cubic specimens. A total of $90 \mathrm{cyl}-$ inders having 6 inch. dia and 12 inch. height was cast (45 each for concrete crushing strength and tensile strength). Similarly, to conduct the permeability test for concrete, 15 cubes were prepared and cured for 28 days to check the water permeability for different mixes of concrete.

German Standard DIN-1048-V has a different approach to determine water permeability as done in other studies $[9,16,22]$. The testing apparatus used for water penetration is shown in Fig. 4, which had the capacity of testing three specimens at a time. After the specimens were fixed in the test cells, the water pressure of 5 bar was applied for $72 \mathrm{~h}$. Water pressure was balanced by the connection of the water tank to an air compressor through a valve.

Three cube specimens were tested at a time for control and sand replacement mixes. Shortly after 3 days, the

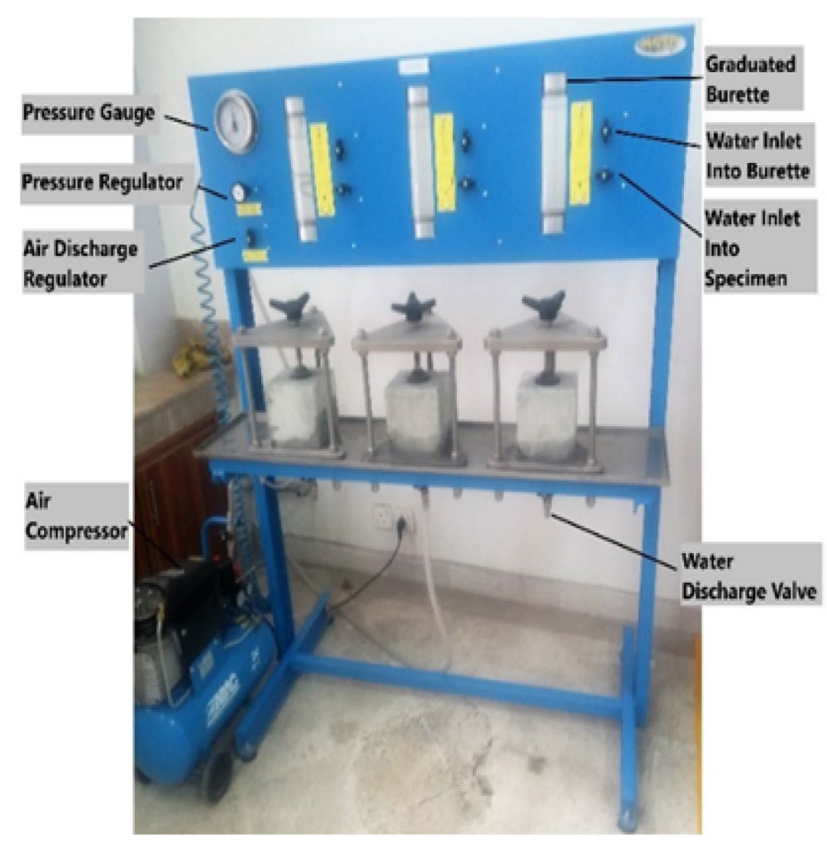

Fig. 4 Water permeability test setup specimen is removed from the chamber and cut in half to visually see the depth of penetration of water. The difference of the maximum depth of penetration between the two halves is very less, so the higher depth value was finalized out of two halves. Figure 5 shows the split cube specimen which is marked to show max penetration.

\section{Results and discussion}

\subsection{Workability}

The most suitable procedure to measure the workability of freshly mixed concrete is by slump test. Therefore, it is mostly used in the field at construction sites. The test results indicate that the target slump for the control specimen was achieved, i.e., 3.54 inch. The results are graphically shown in Fig. 6. The linear relation between a slump and replacement percentage is very significant as regression value $\left(R^{2}=0.96\right)$.

The slump of mixes with WMP was found to be less than the control mix and was relatively stiffer and hard. Several factors affect the workability of concrete like water content, shape, and texture of aggregates, grading, and mix proportions of fine to coarse aggregates and characteristics of cement. When sand is replaced with WMP at different percentages, the number of finer particles and its surface area increases which further demands more water to maintain the workability of concrete. The w/c was kept constant in this study, as a result of which slump has decreased. This decreasing trend was likewise seen in an examination by Hebhoub [23], yet slump value did not reach zero which in the current study reaches zero. That trend depends on the properties of materials. The

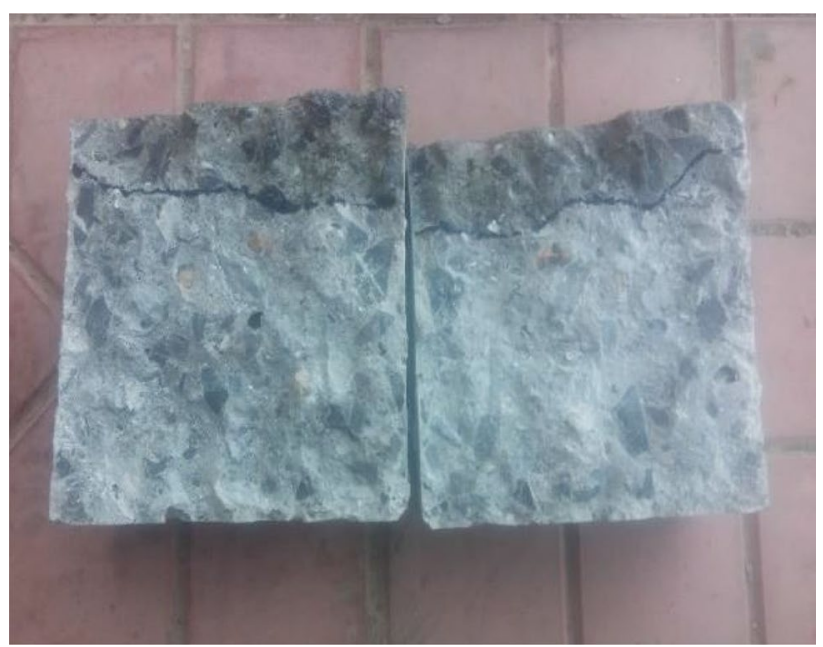

Fig. 5 Split concrete cubes after permeability test 


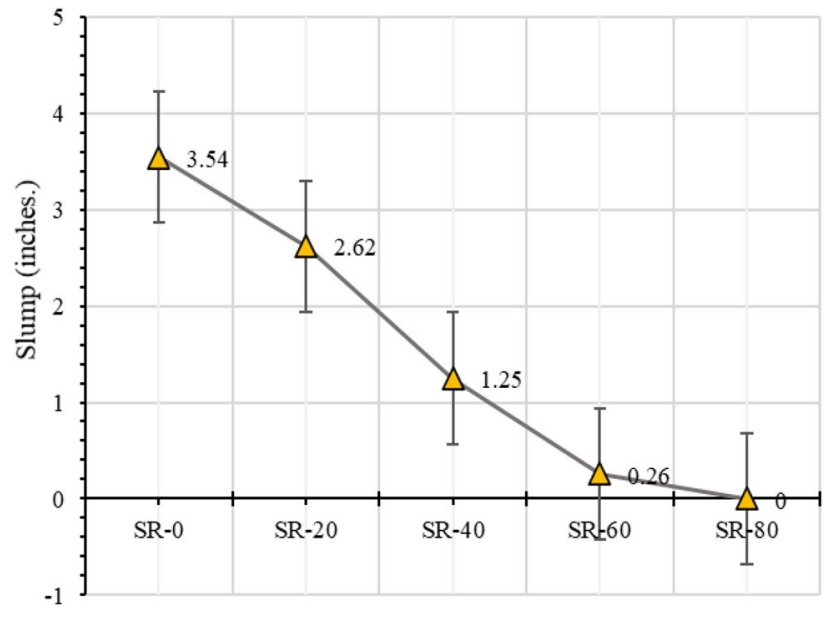

Fig. 6 Variation of slump values for fresh concrete with partial replacement of sand with WMP [49]

materials used in this research are different in terms of bulk density, fineness, specific gravity, shape, and mix proportions. The decreasing trend in the workability was also observed by other authors $[27,36,37,39]$. The w/c values can be adjusted depending on mixed proportions for higher use of WMP primarily based on the demands of construction to compensate for low slump values. On the other hand, plasticizers can also be used on-demand at a higher percentage for improving workability. Even though it is recommended to use plasticizers, it is unlikely to be used because high w/c was used in this research with the ambition of local requirements, for normal strength of $4000 \mathrm{psi}$ and for the ease of a local man.

\subsection{Bulk fresh density}

Bulk fresh density is the combination of densities of materials, mix proportions, water content, and hydration degree. Fresh batches of concrete were weighted in standard cylinders soon after they were prepared. Figure 7 shows the variation graph of bulk fresh density of all concrete mixes which has regression value $\left(R^{2}=0.99\right.$ for linear relationship). It is observed that the bulk fresh density of concrete decreases with the addition of WMP. It is because bulk density and SSD specific gravity of WMP were found to be lesser than those of sand utilized in concrete. In comparison with the studies $[10,22,23,25]$, whether the trend is significant or not, it can be fairly stated that the bulk density of WMP is a contributing factor to unit weight of concrete and its value may differ depending on the source. Besides the reason that the density of WMP was lower than sand, the high decrease at SR 80 is more related to issues in the compaction process because of constant W/C and

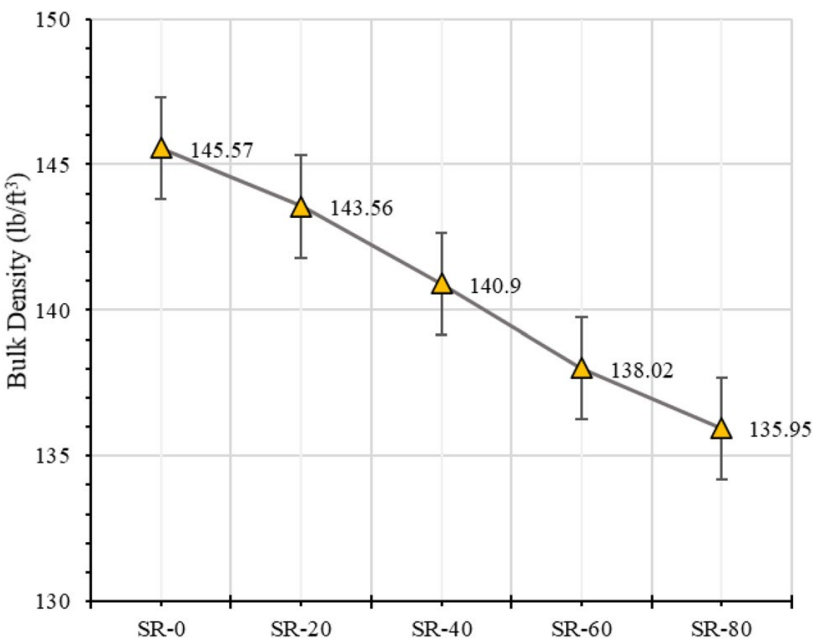

Fig. 7 Bulk density variation of different concrete mixes [44]

imbalance in the gradation of aggregates which creates pores within the structure.

\subsection{Compressive strength}

The application of the concrete in the structural members is because it has considerable high compressive strength, which makes it suitable for many structural members. The compressive strength is influenced by many factors which include $w / c$, gradations of aggregate or grain size distribution of aggregates, surface texture, strength, and maximum size of aggregates $[1,55]$. The WMP type also plays an important role in the compressive strength of the concrete. It was noted during the experimental program that concrete mixtures, with WMP, show increased strength at various ages, even at a high percentage, replacement as $60 \%$ has shown improved results when compared with the control mix. Table 7 shows the values of the compressive strength achieved by the various mixes of concrete. It is shown that SR-20, SR-40, and SR-60 mixes achieved their design strength earlier to even 14 days.

The control concrete mix was designed for 4000 psi at 28 days. Concrete gains its strength rapidly in the initial days after casting. The 14 days/28 days compressive

Table 7 Achieved compressive strength at different ages

\begin{tabular}{llll}
\hline Concrete mix & \multicolumn{3}{l}{ Compressive strength (psi) } \\
\cline { 2 - 4 } & 14 days & 28 days & 70 days \\
\hline SR-0 & 3551.19 & 3916.32 & 3953.70 \\
SR-20 & 4300.93 & 4808.69 & 5313.14 \\
SR-40 & 4966.21 & 5426.19 & 5750.73 \\
SR-60 & 4514.03 & 4896.05 & 5309.25 \\
SR-80 & 2128.38 & 2271.31 & 2592.25 \\
\hline
\end{tabular}


strength ratio is high as $90 \%$; still concrete continues to gain strength after that period, but that rate of gain in compressive strength is very less compared to that in 28 days. The 70 days $/ 28$ days compressive strength ratio obtained was $100.9 \%$, which shows an approximate $1 \%$ increase from 28 to 70 days. At $20 \%$ replacement, there is a $21.12 \%$ increase in the strength of the concrete at 14 days as compared to control mix (SR-0), $22.78 \%$ at 28 days, and $34.38 \%$ at 70 days. The replacement of sand with $40 \%$ WMP showed maximum strength gain which was $39.85 \%$ at 14 days, $38.55 \%$ at 28 days, and $45.45 \%$ at 70 days. The result is attributed to the fact that WMP is an inert material [1] and acts as filler material as the size of the WMP particles was less than most of the sand particles. The ultra-fine marble particles fill the voids in concrete which gives a compact structure and reduces the porosity of concrete in the process which was proved in a study by Demirel [33]. Both SR-20 and SR-40 mixes achieved the design strength at 14 days. It is observed that with the addition of WMP, the trend of strength gaining process is similar to control specimen which up to 14 days ( 14 days/28 days) is comparatively higher than $28-70$ days ( 70 days/28 days). It is speculated in studies $[24,27]$ that the filler effect of the WMP enhances the cement matrix and binding properties are developed due to the hydration of calcite and $C_{3} A$ which explains the early design strength achievement for recycled concrete. In the whole process, inter-particle voids are filled to the point where the bond achieved between cement and aggregates is strong, and hence, a maximum strength gain is achieved.

The strength continued to increase up to $60 \%$ replacement. The increase in strength was $27.11 \%$ at 14 days, $25.01 \%$ at 28 days, and $34.28 \%$ at 70 days. However, there was a $9.1 \%$ strength decrease at 14 days as compared to SR-40, $9.76 \%$ at 28 days, and $7.66 \%$ at 70 days. Beyond $60 \%$ replacement, the decrease in strength follows. At $80 \%$ replacement mix, the result shows a $40.07 \%$ decrease in the strength of the specimen at 14 days, $42 \%$ at 28 days, and $34.43 \%$ at 70 days. Figure 8 shows the graphical representation of compressive strength values with standard error bars.

Concrete can be viewed as a chain in which cement paste binds aggregates together. The reduction in strength may be attributed to the subjugated balance in the grading of aggregates because the number of fine materials increases. A maximum reduction in compressive strength was found at $80 \%$ sand replacement. In this mix, the slump was zero, as a result of which the necessary water was already entrapped by the particles and it needed more water for the flow, which led to the creation of intra-particle voids, hence, decreasing the compressive strength.

Figure 9 presents the summarized gain in strength of concrete at 14,28 , and 70 days of curing at different

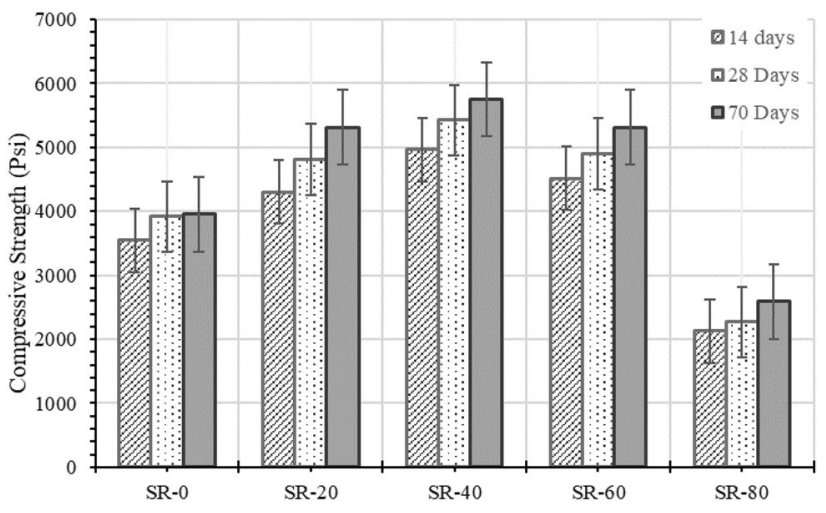

Fig. 8 Compressive strength of concrete at various stages of testing as per ASTM C39 [51]

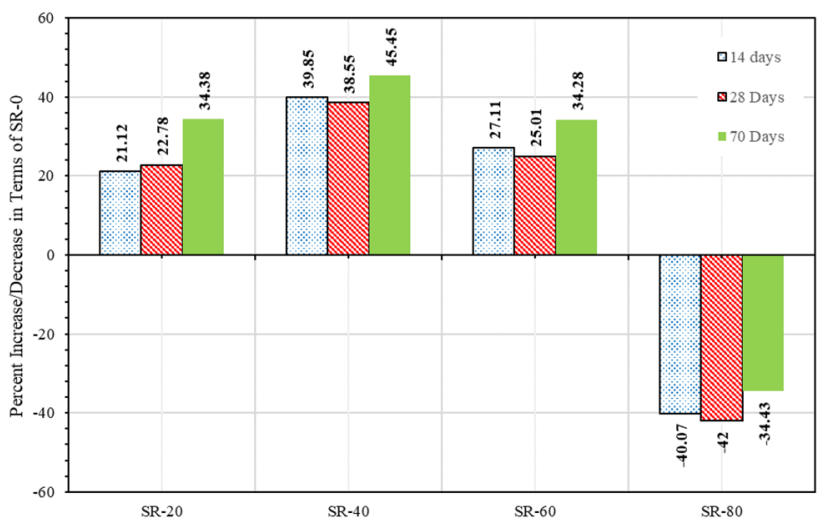

Fig. 9 Percent gain in the compressive strength in terms of SR-0 mix

substitution percentages. The compressive strength gain is calculated according to the compressive strength of recycled concrete and the compressive strength of control concrete. It is clear that the strength is gained significantly up to $60 \%$ substitution and the maximum gain of strength is obtained at $40 \%$ replacement for all ages. When compared with SR-0, a maximum increase of approximately $45 \%$ was observed at 70 -day testing for $40 \%$ replacement of sand and a maximum decrease of $40 \%$ was observed at 14-day testing for $80 \%$ replacement.

\subsection{Splitting tensile strength}

It is essential to know the behavior of concrete under tensile loads with WMP as a partial sand replacement since the tensile strength of any concrete mix is less than its compressive strength. It was found that WMP had no significant impact on concrete tensile strength.

Splitting tensile strength was maximum in $20 \%$ replacement and for other mixes yields approximately the same 
Table 8 Split tensile strengths of mixes at different ages

\begin{tabular}{llll}
\hline Concrete mix & \multicolumn{3}{l}{ Split tensile strength (psi) } \\
\cline { 2 - 4 } & 14 days & 28 days & 70 days \\
\hline SR-0 & 376.29 & 425.66 & 471.87 \\
SR-20 & 429.63 & 454.9 & 478.34 \\
SR-40 & 397.67 & 430.22 & 436.75 \\
SR-60 & 375.70 & 410.75 & 393.85 \\
SR-80 & 339.27 & 366.52 & 361.97 \\
\hline
\end{tabular}

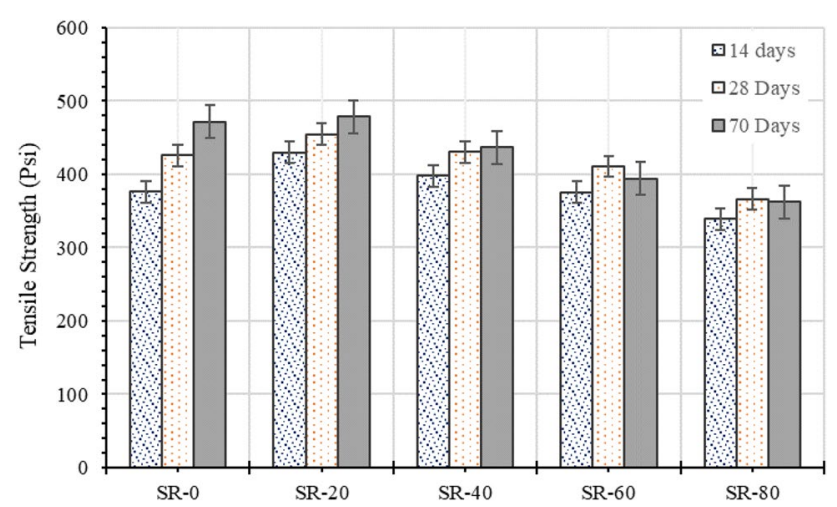

Fig. 10 Tensile strength of concrete at various stages of testing [57]

result as shown in Table 8. The result is attributed to the concrete's weakness in tension because of the microcracks which convert into macrocracks as the tensile displacement increases [56]. As stated in the research [23], the simple tensile test does not measure the bond strength at the aggregate interface, but it is possible to compare the effect of the aggregates substitution which is why no significant changes are found with high substitution rate in comparison with compressive strength results. However, it may be because of coarser sand that was used in the current study with very fine WMP; as a result, tensile strength decreases beyond $20 \%$ replacement. Figure 10 shows the comparison of the tensile strength at various ages of testing.

The tensile and compressive strength values were utilized in developing a relationship between both the strengths of various ages. Table 9 shows that the tensile strength for SR-0 was approximately between 10 and $12 \%$ of the compressive strength for the control mix at different ages of testing. With the increase in WMP in concrete, the ratio of tensile strength to compressive strength reduces as compressive strength increases up to $60 \%$ replacement. Further, it was observed that for $80 \%$ use of WMP, the ratio has increased from SR- 0 because there was a considerable drop in the compressive strength at $80 \%$ use of WMP as fine aggregate which resulted in a higher ratio of tensile to compressive strength percentage. For all the concrete mixes, the tensile strength ranged from approximately
Table 9 Splitting tensile strength in percent of compressive strength

\begin{tabular}{lccc}
\hline Concrete mix & \multicolumn{3}{l}{$\begin{array}{l}\text { Splitting tensile strength in percent of com- } \\
\text { pressive strength (\%) }\end{array}$} \\
\cline { 2 - 4 } & 14 days & 28 days & 70 days \\
\hline SR-0 & 10.6 & 10.87 & 11.93 \\
SR-20 & 9.99 & 9.46 & 9 \\
SR-40 & 8.01 & 7.93 & 7.59 \\
SR-60 & 8.32 & 8.39 & 7.42 \\
SR-80 & 15.94 & 16.14 & 13.96 \\
\hline
\end{tabular}

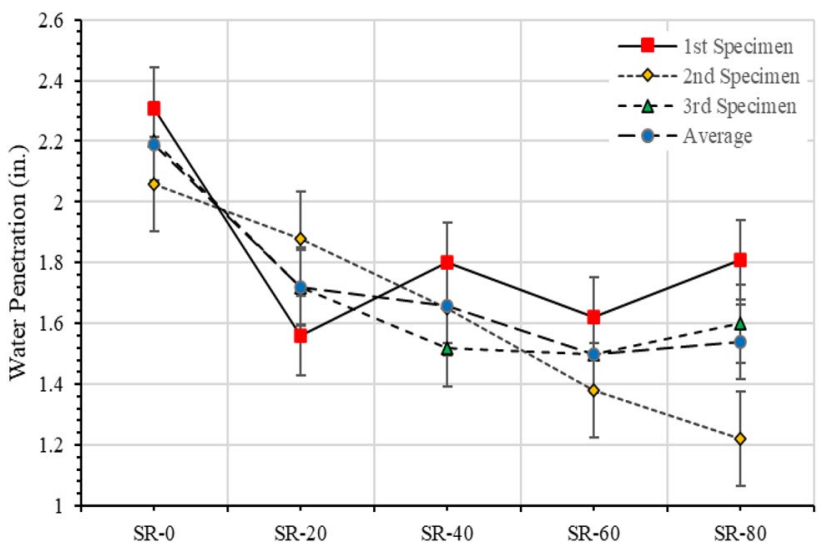

Fig. 11 Water penetration test value for each mix [54]

$8-16 \%$ of their relative compressive strengths at different ages.

\subsection{Water penetration}

The values for water penetration were taken after testing three specimens each. Figure 11 shows the graphical representation of the maximum depth of water penetration values for individual specimens and their average separately. There is a reduction in water penetration depth for all concrete specimens with WMP. The penetration occurred in all control specimens was maximum, and it decreased with WMP addition. The maximum decrease in average penetration depth was observed at a $60 \%$ replacement level. This result is due to WMP's filler influence, and pores are packed with WMP, giving less porous mass which ultimately blocks the way for the water to penetrate through concrete. The average penetration in an $80 \%$ replacement mix was marginally higher than that of the SR-60 mix. The penetration had increased in the SR-80 mix because of the surface pores in the concrete specimen created due to difficulties in compaction and subjugated balance in the gradation of aggregates. It is safe to say that, with the addition of WMP in concrete, the water 
penetration reduces and hence improves the durability of concrete [9]. Figure 12 shows the water penetration in various types of mixes.

The relationship between compressive strength and water penetration depth at 28 days curing is plotted in Fig. 13. Although compressive strength has increased up to $60 \%$ replacement and water penetration depth has decreased for all mixes as compared to control specimen, it could be said that water penetration tends to decrease with increase in compressive strength, but the correlation between the two is very poor $\left(R^{2}=0.0001\right.$ for linear relationship). This could be explained by the fact that water permeability does not only depend on compressive strength but also on a specific surface, pore size distribution, and connectivity of pores.

To evaluate the rate of passage of water into concrete pores, the depth of water penetration inside the specimen can be converted to its equivalent coefficient of water permeability using Valenta's equation [58]. It is

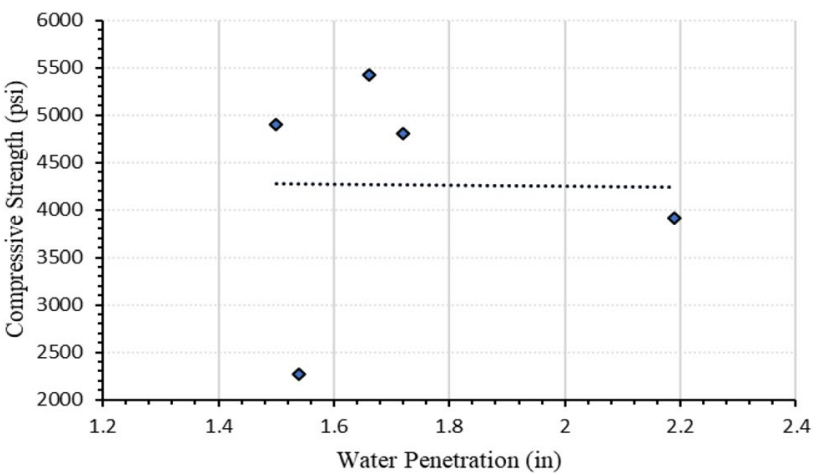

Fig. 13 The relationship between compressive strength and water penetration depth
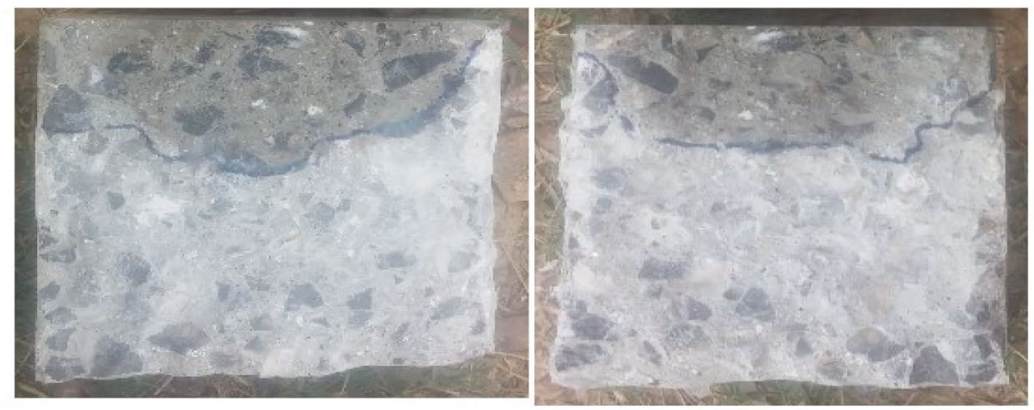

SR-0 Penetration

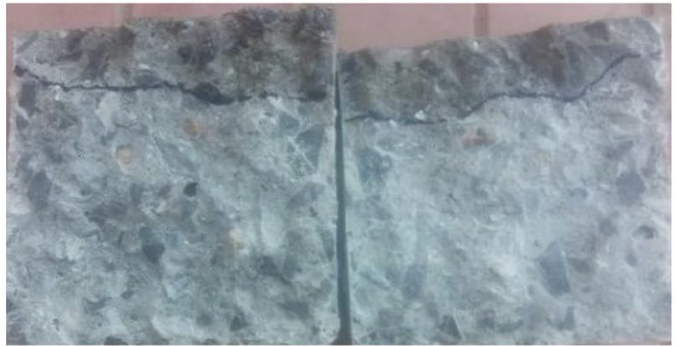

SR-20 Penetration

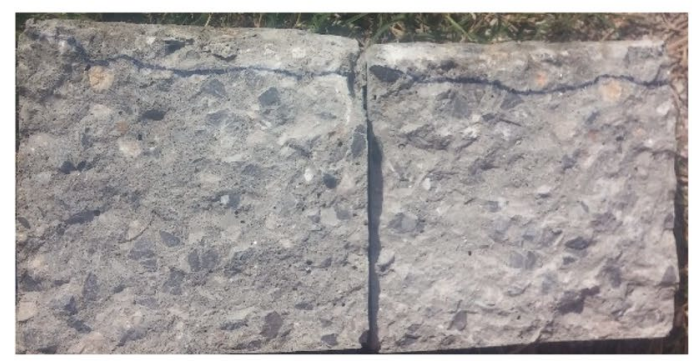

SR-60 Penetration

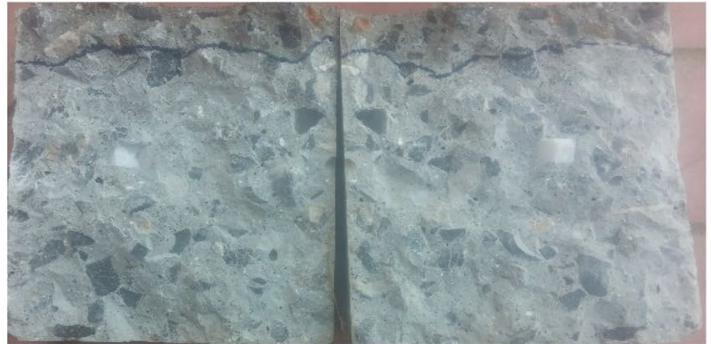

SR-40 Penetration

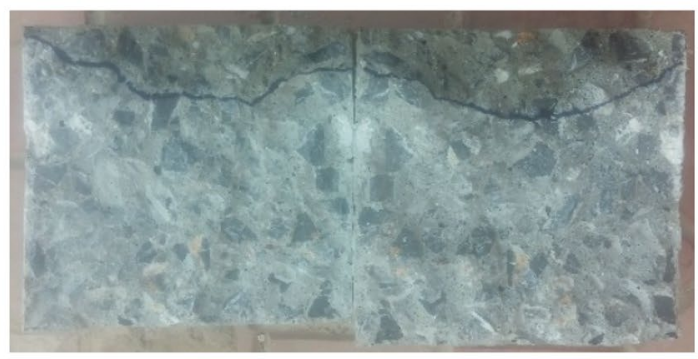

SR-80 Penetration

Fig. 12 Water penetration samples of a different mix of WMP are split into half to read the water penetration value 


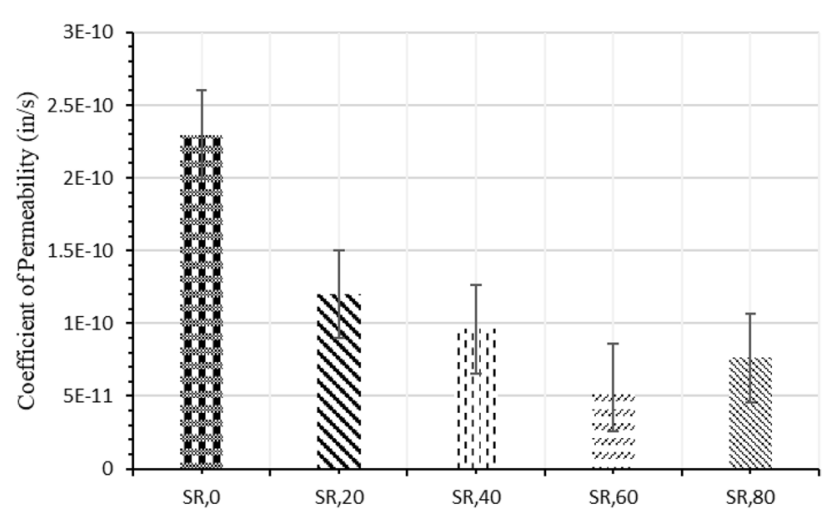

Fig. 14 Coefficient of permeability for various mixes

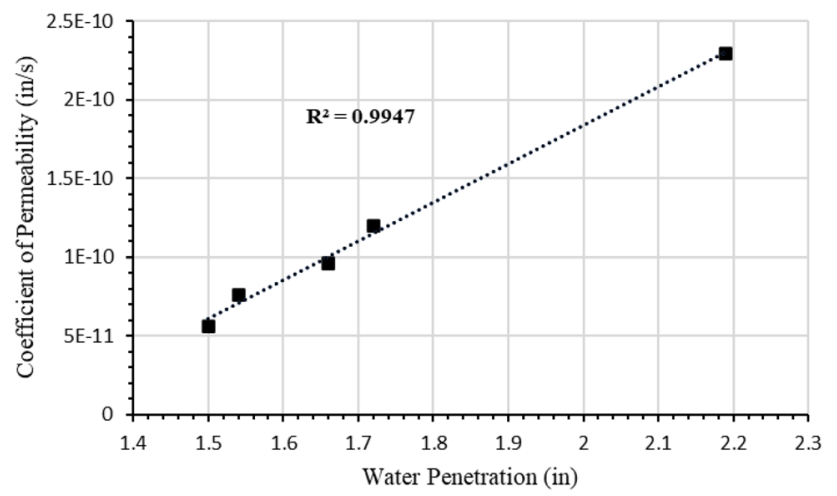

Fig. 15 The relationship between water penetration depth and coefficient of permeability

important to explain the connection between water penetration and pore size distribution.

$\left[k(\mathrm{in} / \mathrm{sec})=\frac{e^{2} v}{2 h t}\right] \rightarrow$ ValentaEquation

In the equation, " $e$ " is the depth of penetration of concrete in inches, " $h$ " is the hydraulic head in inches, " $t$ " is the time under pressure in seconds, and $v$ is the fraction of the volume of concrete occupied by pores. The value of " $v$ " represents discrete pores, such as air bubbles, which do not become filled with water except under pressure and can be calculated from the increase in the mass of concrete during the test. The values for coefficient of permeability were calculated which are graphically presented in Fig. 14. The relation between the water penetration and coefficient of permeability was found to be linearly strong $\left(R^{2}=0.99\right)$, as presented in Fig. 15 . Based on the linear relationship between the two, it can be fairly said that water penetration into concrete mixes decreases as the number of fine particles increases.
However, no conclusions can be drawn from the relation between compressive strength and coefficient of permeability or water penetration depth which is not linearly strong. That being said, there is a tendency to say that both are related based on experimental results as compressive strength also increases up to $60 \%$ replacement at which water penetration depth was minimum.

\section{Conclusions and recommendations}

The incorporation of WMP as a fine aggregate in conventional concrete has a positive impact on the concrete properties. The WMP was used as a partial substitute of sand at $20 \%, 40 \%, 60 \%$, and $80 \%$. The workability, bulk density, compressive strength, tensile strength, and water penetration rate of concrete were evaluated. The recycled product results were compared with the control mix (SR-0).

The incorporation of WMP in concrete is one of the viable solutions to protect the environment and natural resources. This research draws the following conclusions:

- The use of constant $\mathrm{w} / \mathrm{c}$ ratio for all mixes resulted in a reduction in the workability when WMP was introduced as a sand replacement in concrete. As compared to SR-0, the overall reductions at $20 \%, 40 \%, 60 \%$, and $80 \%$ replacement were found to be $26 \%, 65 \%, 93 \%$, and $100 \%$, respectively.

- Due to the relatively low density of WMP, the unit weight of concrete was found to be decreased with the increasing percentages of WMP. Less porous concrete was produced as compared to reference concrete with the use of WMP as a partial substitute for sand.

- The compressive strength of concrete was improved with the use of WMP up to $40 \%$ replacement of fine aggregate; beyond this limit, the strength consistently decreased with the increase in WMP in concrete and was thus minimum for $80 \%$ replacement.

- There were no marked variations in the split tensile strengths with the addition of increased percentages, as a substitute to sand.

- The permeability of concrete was found to decrease with the increasing percentages of sand replacement; however, a sudden rise in the permeability was observed at $80 \%$ replacement, which was even lower than the control mix.

- Based on this study, the use of WMP up to $40 \%$ as partial replacement of sand is recommended, as overconsumption reduces the strength and decreases the workability of concrete.

- To achieve good workability, the use of WMP in concrete needed a considerable number of plasticizers. With the WMP rise, the slump decreases. If high con- 
crete workability is required for construction or other purposes, it is recommended to use plasticizers.

\begin{abstract}
Acknowledgements The research presented herein is part of the Bachelor's study of the authors Abdul Ghani, Zeeshan Ali, and Rehan Shah in the Department of Civil Engineering of UET, Peshawar (Jalozai Campus), under the supervision of Engr. Fasih Ahmed Khan. The authors are sincerely grateful to the anonymous reviewers for their valuable feedback that helped in the improvement of the quality of the paper. Besides our advisor, we would also like to show our gratitude to Dr. Sajjad Wali Khan, Associate Professor, UET Peshawar, for sharing his pearls of wisdom with us during this research. We are also immensely grateful to Dr. Mohammad Javed, Chairman, UET Peshawar (Jalozai Campus), who supported us throughout the research period. Finally, we would like to thank our parents for giving us lots of love and prayers and supporting us financially to carry out all the experimental work throughout our research work.
\end{abstract}

\section{Compliance with ethical standards}

Conflict of interest The authors declared no potential conflicts of interest concerning the research, authorship, and/or publication of this article.

\section{References}

1. Alyamaç KE, Aydin AB (2015) Concrete properties containing fine aggregate marble powder. KSCE J Civ Eng 19(7):2208-2216

2. Korai MA (2010) A report on marble and granite. Trade Development Authority of Pakistan, Karachi

3. Khan Z, Umar M, Shahzada K, Ali A (2017) Utilization of marble dust in fired clay bricks. J Environ Monit 17:1-10

4. Division S (2017) Pakistan statistical yearbook. Pakistan Bureau of Statistics, Islamabad

5. Sarkar R, Das SK, Mandal PK, Maiti HS (2006) Phase and microstructure evolution during hydrothermal solidification of clayquartz mixture with marble dust source of reactive lime. J Eur Ceram Soc 26(3):297-304

6. Singh M, Choudhary K, Srivastava A, Singh Sangwan K, Bhunia D (2017) A study on environmental and economic impacts of using waste marble powder in concrete. J Build Eng 13:87-95

7. Varadharajan S (2020) Determination of mechanical properties and environmental impact due to inclusion of flyash and marble waste powder in concrete. Structures 25:613-630

8. Khodabakhshian A, de Brito J, Ghalehnovi M, Asadi Shamsabadi E (2018) Mechanical, environmental and economic performance of structural concrete containing silica fume and marble industry waste powder. Constr Build Mater 169(2018):237-251

9. Ulubeyli GC, Bilir T, Artir R (2016) Durability properties of concrete produced by marble waste as aggregate or mineral additives. Procedia Eng 161:543-548

10. Gencel O, Ozel C, Koksal F, Erdogmus E, Martínez-Barrera G, Brostow W (2012) Properties of concrete paving blocks made with waste marble. J Clean Prod 21(1):62-70

11. Prasadsharma DDKSEG (2017) Feasibility of marble waste utilization in buildings to save environment. Int J Emerg Trends Sci Technol 04(06):5301-5304

12. Khan S, Haq F, Saeed K (2012) Pollution load in industrial effluent and ground water due to marble industries in district Buner, Khyber pakhtunkhwa, Pakistan. Int J Recent Sci Res 3(5):366-368
13. Shah W, Nafees M (2016) Marble waste: a problem or a resource? In: Sustainable utilization of natural resources, pp 3-4

14. Iqbal $\mathrm{M}$ et al (2018) The effects of marble industries effluents on water quality in Swat, Northern Pakistan. J Biodivers Environ Sci 13(1):34-42

15. Sadek DM, El-attar MM, Ali HA (2016) Reusing of marble and granite powders in self-compacting concrete for sustainable development. J Clean Prod 121:19-32

16. Khaliq SU, Shahzada K, Alam B, Bilal F, Zeb M, Akbar F (2016) Marble powder's effect on permeability and mechanical properties of concrete. Int J Civ Environ Eng 10(4):537-542

17. Rodrigues R, De Brito J, Sardinha M (2015) Mechanical properties of structural concrete containing very fine aggregates from marble cutting sludge. Constr Build Mater 77:349-356

18. Talah A, Kharchi F, Chaid R (2015) Influence of marble powder on high performance concrete behavior. Procedia Eng 114:685-690

19. Molnar LM, Manea DL (2016) New types of plastering mortars based on marble powder slime. Procedia Technol 22:251-258

20. Chiemela C, Walter I, Ogedi I, Peter O, Mong O (2014) Comparing the compressive strengths of concrete made with river sand and quarry dust as fine aggregates. Int Lett Nat Sci 20:179-189

21. Okonkwo VO, Arinze Emmanuel E (2018) A study of the effect of aggregate proportioning on concrete properties. Am J Eng Res (AJER) 7(4):61-67

22. Sardinha M, De Brito J, Rodrigues R (2016) Durability properties of structural concrete containing very fine aggregates of marble sludge. Constr Build Mater 119:45-52

23. Hebhoub H, Aoun H, Belachia M, Houari H, Ghorbel E (2011) Use of waste marble aggregates in concrete. Constr Build Mater 25(3):1167-1171

24. Cagin G, Artir R (2015) Properties of hardened concrete produced by waste marble powder. Procedia Soc Behav Sci 195:2181-2190

25. Kabeer KISA, Vyas AK (2018) Utilization of marble powder as fine aggregate in mortar mixes. Constr Build Mater 165:321-332

26. Vaidevi C, Kala TF, Kalaiyarrasi ARR (2020) Mechanical and durability properties of self-compacting concrete with marble fine aggregate. Mater Today Proc 22:829-835

27. Aliabdo AA, Abd Elmoaty AEM, Auda EM (2014) Re-use of waste marble dust in the production of cement and concrete. Constr Build Mater 50:28-41

28. Chavhan PJ, Bhole SD (2014) To study the behaviour of marble powder as supplementry cementitious material in concrete. ljera 4(4):377-381

29. Arunakanthi E (2017) Experimental study on workability and strength characteristics of concrete containing waste marble aggregate along with marble slurry powder. Int J Sci Technol Eng IJSTE 3(09):31-34

30. Shreyas K (2017) Impact of marble dust on cement concrete. Int J Sci Technol Eng IJSTE 4(6):6-11

31. Hameed S, Sekar S (2014) Properties of green concrete containing quarry rock dust and marble sludge powder as fine aggregate. ARPN J Eng Appl Sci 4:83-89

32. Baboo Rai DS, Naushaad K, Abhishek KR, Rushaad T (2011) Influence of marble powder/granules in concrete mix. Int J Civ Struct Eng 1(4):827-834

33. Demirel B (2010) The effect of the using waste marble dust as fine sand on the mechanical properties of the concrete. Int J Phys Sci 5(9):1372-1380

34. Shukla A, Gupta N, Gupta A (2020) Development of green concrete using waste marble dust. Mater Today: Proc 26(2):2590-2594

35. Singh M, Srivastava A, Bhunia D (2019) Long term strength and durability parameters of hardened concrete on partially 
replacing cement by dried waste marble powder slurry. Constr Build Mater 198:553-569

36. Ashish DK (2018) Feasibility of waste marble powder in concrete as partial substitution of cement and sand amalgam for sustainable growth. J Build Eng 15:236-242

37. Khyaliya RK, Kabeer KISA, Vyas AK (2017) Evaluation of strength and durability of lean mortar mixes containing marble waste. Constr Build Mater 147:598-607

38. Sutcu M, Alptekin H, Erdogmus E, Er Y, Gencel O (2015) Characteristics of fired clay bricks with waste marble powder addition as building materials. Constr Build Mater 82:1-8

39. Vardhan K, Goyal S, Siddique R, Singh M (2015) Mechanical properties and microstructural analysis of cement mortar incorporating marble powder as partial replacement of cement. Constr Build Mater 96:615-621

40. Sounthararajan VM, Sivakumar A (2013) Effect of the lime content in marble powder for producing high strength concrete. ARPN J Eng Appl Sci 8(4):260-264

41. Ergün A (2011) Effects of the usage of diatomite and waste marble powder as partial replacement of cement on the mechanical properties of concrete. Constr Build Mater 25(2):806-812

42. Aruntaş HY, Gürü M, Dayi M, Tekin I (2010) Utilization of waste marble dust as an additive in cement production. Mater Des 31(8):4039-4042

43. A. C184-94e1 (1994) Standard test method for fineness of hydraulic cement by the $150-\mu \mathrm{m}$ (No. 100) and 75- $\mu \mathrm{m}$ (No. 200) sieves. ASTM International, West Conshohocken

44. ASTM C127-15 (2015) Standard test method for relative density (specific gravity) and absorption of coarse aggregate. ASTM International, West Conshohocken

45. A. C566-19 (2019) Standard test method for total evaporable moisture content of aggregate by drying. ASTM International, West Conshohocken

46. ASTM C29/C29M-17a (2017) Standard test method for bulk density ('unit weight') and voids in aggregate. ASTM International, West Conshohocken

47. ASTM C136/C136M-19 (2019) Standard test method for sieve analysis of fine and coarse aggregates. ASTM International, West Conshohocken
48. ASTM C128-15 (2015) Standard test method for relative density (specific gravity) and absorption of fine aggregate. ASTM International, West Conshohocken

49. ASTM C143/C143M-15a (2015) Standard test method for slump of hydraulic-cement concrete. ASTM International, West Conshohocken

50. ASTM C138/C138M-17a (2013) Standard test method for density (unit weight), yield, and air content (gravimetric). ASTM International, West Conshohocken

51. ASTM C39/C39M-18 (2018) Compressive strength of cylindrical concrete specimens. ASTM International, West Conshohocken

52. ASTM C192/C192M-19 (2019) Standard practice for making and curing concrete test specimens in the laboratory. ASTM International, West Conshohocken

53. ASTM(C-496) (2017) Standard test method for splitting tensile strength of cylindrical concrete specimens. In: ASTM International, West Conshohocken

54. DIN (1048-V) (XXXX) Determination of Permeability of Concrete. In: German standard

55. Shetty MS (2005) Concrete technology theory and practice, 2005th edn. Rajendra Ravindera Printers, New Delhi

56. Mindess S, Young JF, Darwin D (2003) Concrete. Prentice Hall, Upper Saddle River

57. ASTM C496, ASTM C496/C496M-17 (2017) Standard test method for splitting tensile strength of cylindrical concrete specimens. ASTM International, West Conshohocken

58. Valenta O (1970) The permeability and durability of concrete in aggressive conditions. In: Proceedings of 10th international congress on large dams, pp 103-117

Publisher's Note Springer Nature remains neutral with regard to jurisdictional claims in published maps and institutional affiliations. 